\title{
Percentual de recursos públicos para a educação: compromisso irrevogável do PIB
}

Percentage of public resources for education: an irrevocable commitment of GNP

\section{João A.C. Monlevade ${ }^{1}$}

\section{Resumo:}

Este artigo se apresenta como uma contribuição para o aperfeiçoamento da estrutura formal do Plano Nacional de Educação, constante do Anexo do Projeto de Lei n 8.035, de 2010. O trabalho particularmente discute a questão do financiamento da educação, de maneira a se dedicar à análise e proposição de novo conteúdo para a Meta 20 do referido plano.

Palavras-chave: Plano Nacional de Educação; Financiamento da Educação; 10\% do PIB.

\begin{abstract}
:
This article is presented as a contribution to the improvement of the formal structure of the National Education Plan, in the annex of Law Project n. 8035/2010. The work particularly discusses the issue of education funding in order to devote to the analysis and proposal of new content for the item 20 of the plan.

Keywords: National Education Plan; Education financing; 10\% GNP.
\end{abstract}




\section{Introdução: uma Metodologia de Aperfeiçoamento para o PNE}

O que proponho com este artigo - fruto inacabado de muito diálogo e longa reflexão sobre textos legais e propostas legislativas - é, antes de tudo, uma contribuição para o aperfeiçoamento da estrutura formal do Plano Nacional de Educação (PNE), constante do Anexo do Projeto de Lei n ${ }^{\circ}$ 8.035, de 2010.

Como tem sido amplamente festejado, reduziram-se as quase trezentas metas do PNE de 2001-2010, para as vinte do PNE ora em tramitação na Câmara dos Deputados. $\mathrm{Na}$ mesma lógica, penso que poderiam resumirse em quinze, condensando as que tratam da Educação de Jovens e Adultos e da Educação Superior. A verdadeira questão, porém, não está aí: é necessário, para se atingir os objetivos do Plano, que as metas, além de claras, comportem marcos gradativos em seus indicadores quantitativos, e que, mais que tudo, estejam "amarradas" por estratégias de responsabilidade definida entre os atores da República Federativa.

Por exemplo, se é mantida a meta de atendimento a $50 \%$ da demanda potencial por creches, e sabendo-se que as matrículas em 2010 não atingiam a $25 \%$ da população de zero a três anos, é fundamental saber como devemos estar no quinto ano de vigência do Plano - inclusive quanto ao percentual de crianças atendidas por instituições privadas com e sem fins lucrativos - e que responsabilidades administrativas e financeiras serão assumidas por estratégias da União, dos Estados e dos Municípios. Na realidade, nesse e em outros exemplos, de nada adiantaria a meta ser de $50 \%, 70 \%$ ou mesmo $100 \%$ (como ocorre em relação às pré-escolas), se não se explicitam as estratégias nos marcos das diversas responsabilidades.

No caso do financiamento, não é diferente. Expliquemos como se distribuem os encargos da União, dos Estados, do Distrito Federal e dos Municípios em relação à oferta e financiamento da educação escolar pública e gratuita.

\section{O Financiamento da Educação Pública: Evolução dos Percentuais Vinculados}

Segundo o art. 212 da Constituição, duas são as principais fontes de financiamento da educação básica e superior pública, que se responsabiliza hoje por perto de 50 milhões de matrículas: as receitas de impostos vinculados à manutenção e desenvolvimento do ensino (MDE) e a contribuição social do Salário-Educação.

Desde a Independência, por óbvio, a oferta de escola gratuita foi viabilizada pelo uso da receita de tributos. De 1834 em diante, quando o encargo das escolas primárias e secundárias passou para as Províncias, coube a estas investir crescentes verbas - da receita de seus tributos à educação escolar. Por isso, tanto mais escolas a Província tinha que arrecadava mais impostos e deles investia maior percentual em educação.

Com a crescente urbanização do País, ficou escancarada a desproporção entre a demanda por matrículas e a frágil oferta de recursos. A cada ano, no âmbito da União, de cada Estado e de cada Município, se travava a briga por um orçamento maior para as escolas públicas. Daí a luta, já no século XX, dos pioneiros da educação e de outros brasileiros pela adoção de um percentual de impostos para a MDE no texto constitucional. Em 1934, quando $75 \%$ da população do Brasil morava no campo e $25 \%$ nas cidades, foi estabelecido o primeiro formato de vinculação: $10 \%$ dos impostos da União para a MDE, 20\% dos Estados e 10\% dos Municípios.

Em 1946, certamente em razão do aumento da demanda e da entrada dos Municípios numa oferta mais significativa de escolas públicas, a Constituição fixou uma segunda formatação: $10 \%$ da União, 20\% dos Estados e 20\% dos Municípios.

Contraditoriamente, a Constituição de 1967 - quando a população urbana acabara de ultrapassar a rural - conservou os percentuais de impostos para a MDE dos Estados e Municípios e retirou o dever constitucional da União em investir na educação pública exatamente quando o governo federal passou a arrecadar as maiores receitas da história do País. Daí até 1988 observou-se, a par do aumento de matrícula, um 
significativo corte na qualidade da educação pública e nos salários de seus profissionais.

A luta do Senador João Calmon ainda está na lembrança de muitos de nós, principalmente dos parlamentares de mais mandatos: em 1983 emplacou sua Emenda, que fixou 13\% dos impostos da União, 25\% dos Estados e 25\% dos Municípios.

Finalmente, a Constituição de 1988 dispôs que $18 \%$ dos impostos da União, 25\% dos Estados e 25\% dos Municípios se aplicassem em MDE - o que foi reafirmado pelo art. 69 da Lei no 9.394, de 1996 - a Lei de Diretrizes e Bases da educação nacional.

Quanto ao Salário-Educação, a história é mais curta e mais simples, tendo evoluído na mesma lógica: em 1964 foi criado o percentual de 1,4\% na folha de contribuição dos empregados, destinado ao ensino primário de quatro anos; em 1972, com a ampliação do ensino obrigatório para oito anos, a alíquota passou a ser de 2,5\% - que se mantém até hoje, embora sua destinação deva cobrir toda a educação básica - de dezessete anos.

\section{O referencial ao PIB: do ex-post ao ex-ante}

Tanto no caso dos impostos como no do Salário-

Educação percebe-se que não basta um aumento de arrecadação para se fazer face às despesas obrigatórias com a educação pública. Houve, objetivamente, um aumento de percentuais da receita pública aplicados em educação. Isso, por três razões, entre outras: aumento de demanda de escolarização (maior população urbana); aumento de demanda de escolaridade, rumo à educação superior; aumento das exigências de qualidade do processo educativo escolar. Essas razões não somente são fatos (contra os quais não há argumentos), como tendem a se acentuar nos próximos anos. As demandas quantitativas, mesmo com a queda da taxa de natalidade, são crescentes, inclusive numa faixa nova e pouco atendida, a educação infantil. E, de outro lado, as demandas qualitativas se impõem pelo advento de novas tecnologias e pelo imperativo da volta à jornada integral, como única forma provada de se superar o fosso das desigualdades sociais e os desafios da qualidade da aprendizagem.
Ora, nesse contexto, a educação comparada, que analisa os diversos sistemas de educação no concerto das nações, tem recorrido a um índice por todas aceito, para avaliar o esforço de cada uma em adotar políticas públicas na área da educação. Trata-se do percentual do PIB que cada uma aplica em sua rede de ensino, oferecido à população de forma gratuita, pelo menos na faixa de educação obrigatória.

A UNESCO tem-se esmerado em publicar as tabelas desses percentuais de aplicação, que são obtidos ex-post, ou seja, depois de verificado o total de gastos públicos em educação num determinado ano, divide-se esse número pelo Produto Interno Bruto (PIB) do mesmo ano. Embora não se deva esquecer os números absolutos - montante do PIB, carga tributária, população estudantil, para citar os mais importantes - o número relativo, expresso no percentual de recursos públicos aplicados em educação em comparação com o PIB, parece ser um dos indicadores mais importantes para se avaliar a política de educação de determinado país, no conjunto das nações.

É corrente a opinião de que o Brasil tem gasto (ou investido) em educação um percentual baixo em relação a seu PIB - números que vão de $3 \%$ a $5 \%$ nos últimos trinta anos, com subidas e descidas. Assim, foi "natural" se construir na opinião pública, principalmente entre os educadores, um consenso de que se deveria investir mais e mais. De 1999 a 2000, tramitou no Congresso um projeto de lei fixando um PNE com previsão de despesas públicas em educação equivalentes a $10 \%$ do PIB. A Lei $\mathrm{n}^{\circ} 10.172$, de 9 de janeiro de 2001, fixou 7\% - percentual que foi vetado pelo Poder Executivo com razões pífias, que escondiam argumentos tão poderosos quanto impublicáveis.

De 2003 em diante, existe uma sensação de que se aumentou a aplicação em relação ao PIB, por duas razões, entre outras. A primeira foi a do aumento real de arrecadação de impostos, misturado com a implantação dos Fundos do Ensino Fundamental (FUNDEF) e da Educação Básica (FUNDEB) que contribuíram para uma distribuição mais equânime e para um controle social mais visível, embora ineficaz na maioria 
dos entes federados. Focalizando somente o ICMS - tributo de maior receita no Brasil - sua arrecadação em valores correntes partiu de $\mathrm{R} \$$ 94,3 bilhões em 2001 para R $\$ 270,7$ bilhões em 2010 (187\% de aumento), diante de uma inflação decenal pouco superior a 100\% A segunda, muito propalada pela mídia oficial, foi a desativação da DRU (Desvinculação dos Recursos da União), que seqüestrava mais de $20 \%$ dos recursos federais vinculados à MDE. A informação oficial dá conta de que se evoluiu de 3,9\% do PIB em 2003 para 5\% do PIB em 2009.

Nada mais "natural", portanto, que os educadores e outros cidadãos envolvidos na Conferência Nacional de Educação (CONAE), ainda lembrados do veto à meta dos $7 \%$ do PNE e embalados pelo crescimento econômico e aumento dos investimentos no Governo Lula, advogassem que se fixasse no PNE, "pra valer", uma meta de aplicação de 10\% dos recursos públicos em relação ao PIB. Cumpre afirmar que a Emenda Constitucional $n^{\circ} 59$, de 2009, tinha acrescido ao art. 214 o dispositivo de obrigar o PNE a fixar meta de aplicação de recursos relativos ao $\mathrm{PIB}$.

\section{Sete ou dez por cento do PIB para a Educação?}

Na verdade, esse dilema não me parece ser o principal no financiamento da educação pública no Brasil. O nó da questão - e esse é o objetivo deste artigo - é como transformar uma medida de avaliação em uma meta e se garantir a efetividade desta meta numa República Federativa, com dispersão de responsabilidades e de encargos.

O que significa transformar uma medida de avaliação tão ampla e global numa meta objetiva? Uma coisa é ter no orçamento a vinculação de impostos e se projetar a destinação de $25 \%$ ou $30 \%$ para a MDE, mês a mês, dia a dia. Os erros na previsão das receitas têm sido desprezíveis, tal o grau de cientificidade de nossa economia. O difícil se concentra na realização da despesa e sua qualidade como investimento (e não como simples gasto, ou até, desperdício). Mudar o percentual do PIB, porém, de ex-post para exante, é um salto de trapezista. Primeiro, porque não se sabe que PIB o país alcançará até 31 de dezembro. Segundo, porque as receitas e despesas de impostos, de Salário Educação e de outros tributos que comporão o percentual do gasto em educação são sujeitos não só a previsões, como a imprevistos. Terceiro, porque o percentual final de aplicação em educação pública será resultado de diferentes percentuais - da União, do conjunto de 26 Estados e do Distrito Federal e do "pequeno coletivo" de 5.564 Municípios, que variam de mil a onze milhões de habitantes.

Chegar a 7\% em quatro anos - como afirmou a plataforma de Governo Dilma - exige não somente que se construam marcos gradativos anuais (suponhamos, numa primeira hipótese: 5,5\% em 2011; 6\% em 2012; 6,5\% em 2013; e 7\% em 2014), como, principalmente, se saiba qual é o compromisso de cada um dos três conjuntos acima: União, Estados + DF e Municípios. Essa é uma operação de altíssima complexidade, que supõe, inclusive, descobrir qual foi o percentual de cada conjunto no ano base de 2010 (ou de 2011, se o PNE começar a valer em janeiro de 2012; ou de 2012, se for adiado seu início para 2013).

$\mathrm{Na}$ administração pública temos, felizmente, um precedente de sucesso na política de ajuste fiscal: a composição do "superávit primário" como percentual do PIB, formado pelas diferenças entre receita e despesa da União, das Estatais, dos Estados e dos Municípios. Não se pode, portanto, argüir a impossibilidade ou impraticabilidade da mesma estratégia de gestão em relação à educação pública.

Acontece que existe um componente político explosivo (tanto ou mais que no caso do "superávit primário") nesse receituário do financiamento da educação pública, candidamente chamado de "regime de cooperação": quem mais arrecada, a União, tem sido quem menos aplica em MDE, desde que o Brasil é Brasil. E quem tem despendido cada vez mais é, exatamente, quem menos arrecada, o conjunto de Municípios. Como remontar essa equação? Não nos esqueçamos que, nesses momentos, surge a tentação de "mudar a metodologia". Na realidade, bastaria classificar uma serie de gastos 
como "aplicações em educação" e poder-seia ganhar até $1 \%$ do PIB: merenda escolar, bolsafamília, despesas em comunicação, em aposentadorias e pensões de educadores, em capacitação de servidores públicos.

É preciso, ao afirmar a meta e as estratégias, ter conceitos claros e definidos, para, então, distribuir a responsabilidade dos aumentos de encargos de cada conjunto federativo no alcance dos 7, 8,9 ou $10 \%$ do PIB em educação.

Urge adotar-se um conjunto de conceitos e uma metodologia idênticos para todas as contas que comporão a aplicação de recursos públicos em educação. A começar da própria noção e amplitude de "educação". Entre "educação escolar pública" - segundo a LDB - e "educação societária permanente", centenas de rubricas orçamentárias entram em questão.

\section{As responsabilidades da União, dos Estados e do DF e dos Municípios para o aumento progressivo e sustentável do percentual do PIB}

Grosso modo, pela legislação atual, cabe à União a educação superior e profissional; aos Estados o ensino médio e parte do fundamental; aos Municípios, a educação infantil e parte do fundamental; e ao Distrito Federal, a educação básica como um todo. Na realidade, temos mais de meio milhão de matrículas nos cursos superiores de instituições estaduais e alguns milhares de matrículas municipais no ensino médio e estaduais na educação infantil. Sem contar os $15 \%$ de participação da iniciativa privada na educação escolar como um todo, principalmente na educação superior, profissional e infantil. Essa variação de oferta reflete-se na variação dos gastos absolutos, de que decorrem os variados percentuais em relação ao PIB.

Infelizmente, não conto com dados confiáveis quanto aos percentuais de aplicação de recursos de cada um dos conjuntos em relação ao PIB, seja em 2009, seja em 2010. Em 2010, o PIB em valores nominais foi de $\mathrm{R} \$ 3.675$ bilhões. Diz-se que a União, nesse ano, não aportou recursos superiores a 1\% do PIB (R $\$ 36,75$ bilhões). Talvez seja uma questão de interpretação: trata-se do que ela aplicou, diretamente, em sua rede, ou do que ela destinou para a educação escolar, incluindo as transferências? No segundo caso, só para complementação do Fundeb e para as cotas estaduais e municipais do salário-educação foram mais de $R \$ 15$ bilhões. E onde ficam as transferências dos Fundos de Participação (FPE e FPM), dos quais $25 \%$ são destinados à MDE nos Estados e Municípios? Dependendo das interpretações, a União pode ter destinado à educação mais de $2 \%$ do PIB.

Em outras palavras, impõe-se uma uniformização de critérios e um diagnóstico preciso, para se formular as estratégias de aumento de recursos - isso sim, uma necessidade evidente - e reincidente. Não será fácil garimpar, em 2010, a aplicação de mais de $\mathrm{R} \$ 183,75$ bilhões em educação - 5\% do PIB, exatamente o mesmo percentual que registrou, para 2000, Jorge Abraão e Castro, em publicação do IPEA de 2003.

Tanto na hipótese dos 7\% quanto na dos $10 \%$, ousaria propor como medida de aplicação dos recursos públicos arrecadadas por cada conjunto (independente de onde foi investido) a seguinte proporção: quatro décimos da União, quatro dos Estados e DF, e dois dos Municípios. Evidentemente, uma vez conhecidas essas proporções nos balanços de 2010 e 2011, esta proposta estaria sujeita a avaliação e a uma programação de gradatividade, porque no mundo real e nas finanças, não se fazem saltos.

Cumpre, chegando aos "finalmentes" deste texto, descrever as possíveis fontes dos novos investimentos em educação escolar e a enumeração das estratégias gerais, entre as quais se enfatizam o que chamo de "compromissos federais".

\section{Fontes para a Expansão dos Investimentos Públicos}

No âmbito da União, pode-se, além de se majorar levemente o percentual de impostos para MDE (de 18\% para 20\%) e elevar a alíquota do Salário-Educação para 3,5\%, pensar numa vinculação geral gradativa, até $10 \%$ em cinco 
anos, das contribuições sociais para a educação (não somente MDE) - medidas que, a médio prazo, poderiam dobrar a capacidade de investimento da União na educação escolar pública, tanto na superior, quanto na básica, especialmente para aumentar a complementação do Fundeb e ampliar a rede de Universidades e Institutos Federais de Educação, Ciência e Tecnologia.

No âmbito dos Estados, do Distrito Federal e dos Municípios, a proposta seria de generalizar a vinculação de 30\% dos impostos e transferências para a MDE - já praticada por oito Estados e muitos Municípios - e destinar também 30\% dos royalties do petróleo e outros minerais para a MDE. Desses 30\%, 25\% ficariam adstritos à educação básica pública (continuando 20\% redistribuídos pelo Fundeb) e $5 \%$ poderiam ser destinados a qualquer nível, etapa ou modalidade do ensino, a critério do ente federado. Para aumentar a arrecadação de ICMS, seriam revistas as isenções hoje propiciadas pela Lei Kandir em relação aos produtos exportados - o que tem reduzido drasticamente a capacidade de receita de muitos Estados e respectivos Municípios.

Especialmente nos Municípios, seriam potenciados os impostos que derivam da capacidade contributiva dos cidadãos e das empresas: ITR, IPTU, ISS, ITBI e IRRF dos servidores públicos. Numa democracia, o princípio que funda a presença do estado nas políticas sociais é a dos direitos sociais (contrapostos aos serviços como mercadorias) garantidos pela realização da "capacidade contributiva". "A cada um segundo suas necessidades, cobrando de cada um segundo suas potencialidades." É uma irresponsabilidade fiscal convivermos com fortunas de pessoas físicas e jurídicas que não são taxadas, não só pelo IR ou IGF, mas na ponta dos tributos patrimoniais. O ITR e o IPTU são sub-arrecadados, até no próprio Distrito Federal. A informalidade de muitos serviços compromete a receita do ISS e a venalidade dos atores reduz a arrecadação de ITBI e ITCD. Nos países avançados, o imposto sobre herança é um dos maiores financiadores da educação pública. No Brasil, não concorre com $0,5 \%$ dos recursos aplicados em MDE.

\section{Estratégias Gerais e Compromissos Federais}

Uma vez circunscrito o problema do financiamento da educação pública e apontadas as questões envolvidas em sua solução no âmbito do PNE, passamos a tecer considerações mais concretas e propositivas sobre a META 20 e as estratégias para sua consecução no Projeto de Lei $n^{\circ}$ 8.035, de 2010.

Para maior ciência, reproduzo inicialmente o texto do PL:

"Meta 20 - Ampliar progressivamente o investimento público em educação até atingir, no mínimo, o patamar de sete por cento do produto interno bruto do país.

Estratégias

20.1 Garantir fonte de financiamento permanente e sustentável para todas as etapas e modalidades da educação pública.

20.2 Aperfeiçoar e ampliar os mecanismos de acompanhamento de arrecadação da contribuição social do salário-educação.

20.3 Destinar recursos do Fundo Social ao desenvolvimento do ensino.

20.4 Fortalecer os mecanismos e os instrumentos que promovam a transparência e $o$ controle social na utilização de recursos públicos aplicados em educação.

20.5 Definir o custo-aluno-qualdade da educação básica à luz da ampliação do investimento público em educação.

20.6 Desenvolver e acompanhar regularmente indicadores de investimento e tipo de despesa per capita por aluno em todas as etapas da educação pública"(CÂMARA DOS DEPUTADOS, Projeto de Lei 8.035/2010).

À vista das considerações anteriores, proporia a seguinte redação:

Meta 20 "Ampliar progressivamente - investimento de recursos públicos em educação, à razão de 0,5\% anuais, para atingir, em cinco anos, o patamar mínimo de sete por cento do produto interno bruto e, se necessário para o alcance das metas anteriores - segundo avaliação após o quarto ano de vigência do Plano atingir até dez por cento do PIB no decurso da década, tendo como referência a participação da União com $40 \%$ e do conjunto 
de Estados e do Distrito Federal, com outros 40\% dos gastos do País em relação a seu PIB."

Quanto às estratégias, não se descartam as seis, de caráter geral, elencadas no PL. A 20.1 em especial, é de suma importância, por estabelecer política de investimento válida para a sustentabilidade do Plano em todas as esferas da Federação. Sua manutenção justifica, inclusive, a não inserção de uma nova fonte, reclamada pela CONAE (a do Fundo Social do Pré-Sal), em vista de ela não ter ainda consistência fiscal, embora seja desejável e nada desprezível como fonte adicional, principalmente para os anos finais de vigência do novo PNE. Entendo, também, que a 20.6 inclui a explicitação semântica legal dos itens que compõem a MDE e a "aplicação em educação", a ser obedecida em todos os orçamentos e balanços contábeis. Entretanto, faz-se necessário incluir outras estratégias de maior efetividade, que realmente garantam o alcance da meta no marco do quinto ano de vigência do Plano e sejam de compromisso e de comando da União, ainda que com participação, em várias delas, dos outros entes federados.

A primeira diz respeito ao Fundeb, que tem a mesma vigência prevista para o PNE (até 2010):

20.7"Aumentar, nas leis orçamentárias anuais, a complementação da União aos Fundebs estaduais, dos $10 \%$ (dez por cento) atuais em relação à sua receita total, para $20 \%$ (vinte por cento), na razão de $2 \%$ (dois por cento) a cada ano." Para tanto, não é necessária nenhuma mudança na legislação do Fundeb, já que o art.60 do Ato das Disposições Constitucionais Transitórias, em seu inciso VII, prevê a complementação de "no mínimo", 10\% a partir do quarto ano de vigência dos Fundos (2011).

A segunda se refere ao aumento dos recursos vinculados à MDE:

20.8 "Aprovar, no primeiro ano de vigência do PNE, Proposta de Emenda à Constituição, para, no art. 212, aumentar de $18 \%$ para $20 \%$ o percentual de impostos da União destinados à manutenção e desenvolvimento do ensino, bem como de $25 \%$ para $30 \%$ o mesmo percentual de vinculação de impostos e royalties da extração de petróleo e minerais dos Estados, do Distrito Federal e dos Municípios, resguardando que, destes últimos, cinco sextos sejam investidos exclusivamente na educação básica pública."

A terceira tem a ver com o Salário-Educação:

20.9 "Ser encaminhado pelo Poder Executivo, no primeiro ano de vigência do PNE, e aprovado no Congresso Nacional Projeto de Lei aumentando a alíquota de 2,5\% para 3,5\% do Salário-Educação"

A quarta diz respeito à vinculação constitucional de um percentual da receita das contribuições sociais da União à educação - não necessariamente à MDE:

20.10 "Aprovar, até o segundo ano de vigência do PNE, Proposta de Emenda à Constituição para, no art. 212, introduzir parágrafo que disponha sobre a vinculação de $10 \%$ das contribuições sociais da União - com exceção do Salário-Educação - para despesas de capital e de custeio da educação escolar gratuita, pública ou comunitária."

A quinta estratégia se refere a uma mudança explícita na Lei Kandir, para rever as isenções de ICMS cobrado nas operações de circulação de bens exportados, de forma a aumentar a arrecadação de impostos estaduais e sua conseqüente destinação à MDE:

20.11 "Encaminhar e fazer aprovar, até o segundo ano de vigência do PNE, mudança na Lei Complementar $n^{\circ} 89$, de 1996, de forma a reduzir a isenção de ICMS para os produtos exportados, inclusive os bens primários e semi-elaboradas, seja sob forma de seleção dos produtos, seja por aplicação de alíquotas, bem como fazer aprovar o texto da Lei que regulamenta o Imposto sobre Grandes Fortunas e instituir novas alíquotas progressivas do Imposto sobre a Renda, que permitam o aumento da arrecadação de impostos destinados à MDE". Cumpre dizer que cessaram, no todo ou em parte, os motivos que justificavam as isenções da chamada "Lei Kandir". Atualmente, Estados como o Pará e Minas Gerais são substancialmente prejudicados por ver transformadas em lucros de mineradoras e de outras empresas as receitas potenciais de seu ICMS, que, diminuídas, não dão conta das demandas sociais. Quanto ao IGF e ao IR, é uma questão de aproveitar com 
justiça as "capacidades contributivas" e cumprir o mandato constitucional da "progressividade" dos tributos.

A sexta estratégia adicional tem a ver com o uso dos recursos adicionais que serão aplicados em educação. É consenso geral que sem uma robusta valorização salarial dos profissionais da educação e sua dedicação exclusiva a uma escola, não haverá melhoria da qualidade da educação pública:

20.12“Destinar $80 \%$ dos recursos do Fundeb e da receita dos royalties ao pagamento de salários dignos para os profissionais da educação, condicionando-os à dedicação exclusiva a uma escola ou à mesma rede pública da educação básica". Esta estratégia deve ser articulada com as referentes à meta da valorização dos profissionais da educação básica pública, levando em conta o aumento real do valor do Piso Salarial Profissional do Magistério e a implantação do Piso Salarial Nacional para os outros profissionais da educação, elencados no art. 61 da LDB. Podese pensar numa data, a médio prazo, para extinguir o acúmulo de cargos de professor, disposto no art.37 da CF.

A sétima estratégia, que, como as anteriores, envolve compromisso do governo federal, diz respeito à mudança necessária na Lei de Responsabilidade Fiscal, Lei Complementar $n^{\circ}$ 101, de 2000. Por seu texto atual, são fixados limites de gastos com pessoal para os governos da União, dos Estados, do Distrito Federal e dos Municípios. Em que pese as intenções originais de inibir práticas clientelísticas e outros desmandos de gestão, é inconcebível que esses limites (ao redor de 50\% das despesas orçamentárias) impeçam a contratação de mais profissionais em creches e em etapas ou modalidades da educação básica a que a população tem direito. Ou inibam aumentos salariais propiciados por recursos próprios dos Estados e Municípios, inclusive oriundos do Fundeb, que, por disposição constitucional, deve ter $60 \%$ de sua receita aplicada no pagamento de professores em exercício. A questão não é simples, mas é imprescindível a presença, no PNE, de uma estratégia para superar o falso impasse.
20.13 "Fazer aprovar no Congresso Nacional, no primeiro ano de vigência do PNE, Projeto de Lei que flexibilize os limites de gasto com pessoal, no caso dos trabalhadores da educação pública, nos dispositivos da Lei Complementar $n^{\circ} 101$, de 2000, LRF, de forma a permitir a contratação de professores e demais profissionais da educação básica e superior e sua valorização salarial, desde que haja sustentação financeira".

A oitava estratégia é decorrente do novo preceito constitucional em relação ao $\mathrm{PNE}$, que exige o investimento em educação de percentual do PIB. É um procedimento lógico: o que se pretende para o todo (Brasil), tem que se realizar nas partes (Estados, DF e Municípios). Visa assegurar uma metodologia segura de construir o percentual pela soma da mesma relação Plano a Plano - não se descartando a hipótese de em algumas unidades federadas haver um investimento menor em relação ao próprio PIB quando for provada, por diagnóstico científico e atualizado, o investimento maior em outro ente, que possa compensar a diferença e assegurar a média prevista para o País em determinado ano.

20.14 "Incluir nos Planos Estaduais, Municipais e do Distrito Federal, diagnóstico de quanto se aplica em educação - por todos os Poderes Públicos - no respectivo território em relação ao PIB do Estado, do Município ou do Distrito Federal, bem como programar os investimentos próprios e prever os dos outros entes, de forma a atingir no âmbito do território o percentual mínimo pactuado nos marcos gradativos do PNE"'

\section{Conclusão}

Como dito no início deste artigo, foi abordado o financiamento no PNE não somente para analisar suas questões e implicações para a educação básica e superior públicas, mas também para se propor um esforço de integração entre o texto da meta e das estratégias que conduzam à viabilidade material do Plano.

A grande questão para a sociedade e para os políticos é a seguinte: queremos ou não ter 
um PNE viável e coerente - com os sucedâneos Planos Estaduais, Municipais e do Distrito Federal - para ser efetivamente cumprido? A experiência da Lei $n^{\circ}$ 10.172, de 2001, foi desastrosa. Simplesmente seus dispositivos foram ignorados nas leis Orçamentárias da União e dos entes federados. As metas, quando atingidas até 2010, o foram, na maioria, por um movimento social inercial. As que exigiam mudanças de rumo (como as referentes à qualidade da educação pública) ou transformações radicais, não saíram do papel, ou tiveram alcance limitado a poucos entes federados.

Sabemos que este texto tem uma grave limitação. Ele não enfrenta a questão do financiamento das redes privadas de ensino e seu papel no contexto do futuro da educação brasileira, inclusive nos dez anos do PNE. Haveria muito o que analisar a esse respeito, inclusive os condicionantes de classe social que se imiscuem nas políticas de Estado e nas decisões das famílias quando matriculam ou pensam acessar as escolas e as universidades.

Contradições violentas conspiram contra a elaboração e a efetivação de um Plano "pra valer", na linguagem coloquial. Esperamos que esse texto tenha suscitado essas e outras interrogações, que fazem parte do processo penoso de desenvolvimento da sociedade brasileira e de superação de suas históricas e abissais desigualdades, que um Plano, até por definição etimológica, deve fazer. 